\title{
Immunophilin ligands FK506 and cyclosporine A improve neurologic and histopathologic outcome after transient spinal cord ischemia in rabbits
}

\author{
Tsuyoshi Tachibana, MD, PhD \\ Norihiko Shiiya, MD, PhD \\ Takashi Kunihara, MD, PhD \\ Yutaka Wakamatsu, MD, PhD ${ }^{a}$ \\ Akimaro Fabio Kudo, MD, $\mathrm{PhD}^{\mathrm{a}}$ \\ Tomonori Ooka, MD, PhD \\ Satoshi Watanabe, MD, $\mathrm{PhD}^{\mathrm{b}}$ \\ Keishu Yasuda, MD, PhD ${ }^{a}$
}

From the Departments of Cardiovascular Surgery $^{\mathrm{a}}$ and Functional Morphology, ${ }^{\mathrm{b}}$ Hokkaido University Graduate School of Medicine, Sapporo, Japan.

Received for publication Dec 30, 2003; revisions received April 20, 2004; accepted for publication April 22, 2004.

Address for reprints: Norihiko Shiiya, MD, $\mathrm{PhD}$, Department of Cardiovascular Surgery, Hokkaido University Hospital, N14, W5, Kita-ku, Sapporo 060-8648, Japan (E-mail: shiyanor@med.hokudai.ac.jp).

J Thorac Cardiovasc Surg 2005;129:123-8

$0022-5223 / \$ 30.00$

Copyright $\odot 2005$ by The American Association for Thoracic Surgery

doi:10.1016/j.jtcvs.2004.04.047
Background: We comparatively evaluated the protective effect of the immunophilin ligands cyclosporine A (INN: ciclosporin), FK506, and rapamycin on the spinal cord in a rabbit model of transient ischemia. Both cyclosporine A and FK506 inhibit calcineurin, whereas rapamycin does not.

Methods: Thirty-six male New Zealand White rabbits were divided into the following 6 groups: group C, 15 minutes of spinal cord ischemia; group FK, FK506 (1 $\mathrm{mg} / \mathrm{kg}$ ) administered 30 minutes before ischemia; group CsA, cyclosporine A (30 $\mathrm{mg} / \mathrm{kg}$ ) administered 30 minutes before ischemia; group CsA-C, chronic administration of cyclosporine A $(20 \mathrm{mg} / \mathrm{kg})$ for 9 days before ischemia; group R, rapamycin $(1 \mathrm{mg} / \mathrm{kg})$ administered 30 minutes before ischemia; and group $\mathrm{R}+\mathrm{FK}$, rapamycin $(1 \mathrm{mg} / \mathrm{kg})$ administered 20 minutes before FK506 pretreatment $(1 \mathrm{mg} /$ $\mathrm{kg}$ ). Group CsA-C was added because the drug does not readily cross the bloodbrain barrier. Neurologic function was evaluated by Johnson's 5-point scale at 8, 24, and 48 hours after ischemia, and histopathology was assessed 48 hours after ischemia.

Results: At 24 and 48 hours after ischemia, the Johnson score was better in groups FK $(4.0 \pm 1.1), \mathrm{R}+\mathrm{FK}(3 \pm 1.1)$, and CsA-C $(2.7 \pm 1.2)$ than in group $\mathrm{C}(0.8 \pm$ 1.2). Numbers of morphologically intact anterior horn cells were higher in groups FK $(31.3 \pm 9.9), \mathrm{R}+\mathrm{FK}(23.2 \pm 4.5)$, and CsA-C $(18.3 \pm 6.8)$ than in group C (6.3 $\pm 4.3)$.

Conclusions: FK506 and chronic administration of cyclosporine A, but not rapamycin, protect the spinal cord from transient ischemia. Although these results are compatible with inhibition of calcineurin in the mechanism of neuroprotective action of these drugs, other effects through different pathways cannot be excluded before further study.

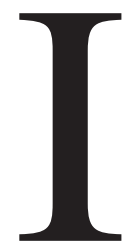

schemic spinal cord injury is a serious complication after operation on the thoracoabdominal aorta. A number of techniques and drugs that may reduce the ischemia-reperfusion injury of the cord have been evaluated both clinically and experimentally, with variable success. Cyclosporine A (INN: ciclosporin) and FK506 are immunosuppressive compounds that are believed to exert their action through binding to small intracellular regulatory proteins called immunophilins (cyclophilins for cyclosporine A and FK binding 
proteins; FK506 binding proteins [FKBPs] for FK506). ${ }^{1}$ When cyclophilin A is bound to cyclosporine A, it inhibits the phosphatase calcineurin, and this results in the inhibition of T-cell activation. Similarly, the immunosuppressive effect of FK506 is mediated mainly through its binding to the 12-kd FKBP (FKBP12), which also results in calcineurin inhibition. In addition to their immunosuppressive properties, these drugs have been shown to protect brain neuronal cells from ischemia/reperfusion injury. ${ }^{2,3}$ In the setting of transient spinal cord ischemia, however, their neuroprotective effects have not been thoroughly evaluated, and only 2 studies were found in MEDLINE that independently studied the effect of cyclosporine A administered after ischemia in a rabbit model ${ }^{4}$ and the effect of FK506 administered before ischemia in a rat model. ${ }^{5}$

We designed this study to compare the protective effect of the immunophilin ligands cyclosporine A, FK506, and rapamycin administered before ischemia in a rabbit model of transient spinal cord ischemia. The protective effect of cyclosporine A given before ischemia and that of FK506 in a different animal model may thus be validated. The effect of rapamycin, which also binds to FKBP12 but does not inhibit calcineurin, was evaluated to help elucidate the role of calcineurin inhibition.

\section{Materials and Methods}

Thirty-nine male New Zealand White rabbits weighing $2.6 \pm 3.3$ $\mathrm{kg}$ were used in this study. The animal protocol was approved by the Hokkaido University Animal Care and Use Committee and was in accordance with the Guide for the Care and Use of Laboratory Animals published by the National Institutes of Health (publication no. 85-23; revised 1985). All experiments were performed in the Research Institute of Hokkaido University School of Medicine.

The experimental model used in this study has previously been described. ${ }^{6}$ Briefly, the animals were anesthetized with intramuscular administration of ketamine hydrochloride $(50 \mathrm{mg} / \mathrm{kg})$ and maintained at $39^{\circ} \mathrm{C}$ (normal value in our animals) with the aid of a heating pad (Asahi Plate Warmer TK-43; Asahi Denshi Inc, Osaka, Japan). The marginal ear vein was cannulated for intravenous drug administration. The median ear artery was cannulated to monitor proximal aortic blood pressure. Arterial blood pressure and rectal temperature were continuously monitored throughout the operation.

After intravenous administration of heparin sodium (100 IU/kg), a 4F angiographic balloon catheter (A024; Goodtec, Huntington Beach, Calif) was introduced through the surgically isolated left femoral artery into the abdominal aorta to $15 \mathrm{~cm}$ from the arteriotomy. This distance was decided so that the tip of the catheter balloon lay just caudal to the left renal artery. This was confirmed at the postmortem examination of the rabbits killed for catheter placement measurements that was performed before our previous study $(n=6)$ and was reconfirmed before the present study $(\mathrm{n}=3)$. Spinal cord ischemia was induced by inflation of the balloon. Aortic occlusion was confirmed by reduction in distal aortic blood pressure, which was measured through the side hole of the balloon catheter. At the end of the operation, catheters were removed, surgical wounds were closed, and rabbits were allowed to recover at ambient temperature and were returned to their cages.

\section{Experimental Protocol}

The rabbits were divided into 6 groups. In the control group (group $\mathrm{C} ; \mathrm{n}=6$ ), rabbits had 15 minutes of spinal cord ischemia, and vehicle was intravenously administered 30 minutes before ischemia. In the FK506 pretreatment group (group FK; n = 6), FK506 $1 \mathrm{mg} / \mathrm{kg}$ was administered 30 minutes before ischemia. In the cyclosporine A pretreatment group (group CsA; $n=7$ ), cyclosporine A $30 \mathrm{mg} / \mathrm{kg}$ was administered 30 minutes before ischemia. One animal in this group died after surgery before neurologic evaluation and was excluded from the analysis. In the cyclosporine A chronic administration group (group CsA-C; $\mathrm{n}=8$ ), cyclosporine A $20 \mathrm{mg} / \mathrm{kg}$ was administered intravenously for 9 days before operation and 30 minutes before ischemia. Two animals in this group died during chronic drug administration before operation and were excluded from the analysis. In the rapamycin pretreatment group (group $\mathrm{R} ; \mathrm{n}=6$ ), rapamycin $1 \mathrm{mg} / \mathrm{kg}$ was administered 30 minutes before ischemia. In group $\mathrm{R}+\mathrm{FK}(\mathrm{n}=6)$, rapamycin $1 \mathrm{mg} / \mathrm{kg}$ was administered 20 minutes before FK506 administration, and FK506 $1 \mathrm{mg} / \mathrm{kg}$ was administered 30 minutes before ischemia. Drugs were dissolved in absolute ethanol containing $400 \mathrm{mg}$ of polyoxyl 60 hydrogenated caster oil $(1 \mathrm{~mL} / \mathrm{mL})$, and the same vehicle was administered in group C.

\section{Neurologic Assessment}

Neurologic function was evaluated at 8, 24, and 48 hours after the operation. Animals were graded on a 5-point scale according to the method of Johnson and associates ${ }^{7}$ : 0, hind-limb paralysis; 1, severe paraparesis; 2, functional movement, no hop; 3, ataxia, disconjugate hop; 4, minimal ataxia; 5, normal function. One member of the research team without knowledge of the treatment graded neurologic function.

\section{Histologic Assessment}

Immediately after neurologic testing, the animals were killed under deep anesthesia with sodium pentobarbital $(50 \mathrm{mg} / \mathrm{kg}$ intravenously), and the spinal cords were quickly removed. They were fixed by immersion in $2 \%$ paraform/aldehyde $/ 15 \%$ picric acid in $0.1 \mathrm{~mol} / \mathrm{L}$ phosphate buffer and embedded in paraffin. Serial transverse sections $(5 \mu \mathrm{m})$ were obtained at the level of L3-4. They were stained with hematoxylin and eosin for histopathologic observations. Numbers of morphologically intact anterior horn cells were calculated in each group and were compared.

\section{Statistical Analysis}

Data are expressed as mean $\pm \mathrm{SD}$. The Mann-Whitney $U$ test was used for nonparametric comparison of the Johnson score between 2 groups. The Kruskal-Wallis test was used for nonparametric comparison of the temporal change in the Johnson score.

\section{Results}

In all groups, the mean distal aortic pressure decreased to less than $20 \mathrm{~mm} \mathrm{Hg}$ after balloon inflation. The rectal temperature decreased by approximately $0.5^{\circ} \mathrm{C}$ during bal- 
loon inflation and returned to the preclamping level within 15 minutes after reperfusion. No significant difference was found in these parameters among the groups at any time point.

\section{Neurologic Outcome}

The average Johnson score after 8 hours was $2.0 \pm 1.1$ in group C, $3.7 \pm 0.8$ in group $\mathrm{FK}, 1.7 \pm 1.0$ in group CsA, $3.2 \pm 0.8$ in group CsA-C, $1.2 \pm 1.3$ in group R, and $3.7 \pm$ 0.8 in group $\mathrm{R}+\mathrm{FK}$ (Figure 1). After 24 hours, the score was $0.8 \pm 1.2$ in group C, $4.0 \pm 1.1$ in group FK, $1.5 \pm 0.8$ in group CsA, $2.7 \pm 1.2$ in group CsA-C, $0.7 \pm 0.8$ in group $\mathrm{R}$, and $3.0 \pm 1.1$ in group $\mathrm{R}+\mathrm{FK}$. After 48 hours, the score was $0.7 \pm 0.8$ in group $\mathrm{C}, 4.0 \pm 1.1$ in group $\mathrm{FK}, 1.5 \pm 0.8$ in group CsA, $2.7 \pm 1.2$ in group CsA-C, $0.7 \pm 0.8$ in group $\mathrm{R}$, and $3.0 \pm 1.1$ in group $\mathrm{R}+\mathrm{FK}$. The differences between groups at 8 hours were not statistically significant. At 24 and 48 hours, the motor function of group FK and group R+FK was significantly better than that in groups $\mathrm{C}, \mathrm{CsA}$, and R. The motor function of group CsA-C was also significantly better than that in groups $\mathrm{C}$ and $\mathrm{R}$ at 24 and 48 hours. The difference between group CsA and CsA-C $(P=.08)$ and between group FK and CsA-C $(P=.07)$ at 24 and 48 hours was not statistically significant.

\section{Histopathologic Outcome}

In groups $\mathrm{FK}$, CsA-C, and $\mathrm{R}+\mathrm{FK}$, many large motor neurons were seen in the anterior horn, in which nuclear structures were retained, nuclei were integrated, and membranes were smooth (Figure 2). In other groups, however, the gray matter had vacuums in places that should be the trace of dead neurons; remaining large motor neurons showed shrinkage, their nuclei showed chromatic agglutination and nucleolar disintegration, and their shape underwent distortion similar to that of the whole cell. The density of glial cells in the gray matter showed the same change.

The average numbers of morphologically intact anterior horn cells in each group are summarized in Figure 3: $6.3 \pm$ 4.3 in group $\mathrm{C}, 31.3 \pm 9.9$ in group $\mathrm{FK}, 10.3 \pm 10.7$ in group CsA, $18.3 \pm 6.8$ in group CsA-C, $12.5 \pm 10.4$ in group $\mathrm{R}$, and $23.2 \pm 4.5$ in group $\mathrm{R}+\mathrm{FK}$. The differences between group $\mathrm{C}$ and groups $\mathrm{FK}, \mathrm{CsA}-\mathrm{C}$, and $\mathrm{R}+\mathrm{FK}$ and those between group $\mathrm{FK}$ and groups $\mathrm{C}, \mathrm{R}$, and CsA were statistically significant (group $\mathrm{C}$ vs group $\mathrm{FK}, P=.0002$; group $\mathrm{C}$ vs group CsA-C, $P=.0044$; group $\mathrm{C}$ vs group $\mathrm{R}+\mathrm{FK}, P<.0001$; group $\mathrm{FK}$ vs group $\mathrm{C}, P=.0002$; group FK vs group $\mathrm{R}, P=.0095$; group $\mathrm{FK}$ vs group $\mathrm{CsA}, P=$ $.0054)$.

\section{Discussion}

The results of this study not only confirmed the neuroprotective effect of FK506 against transient spinal cord ischemia in a different animal model, but also showed for the
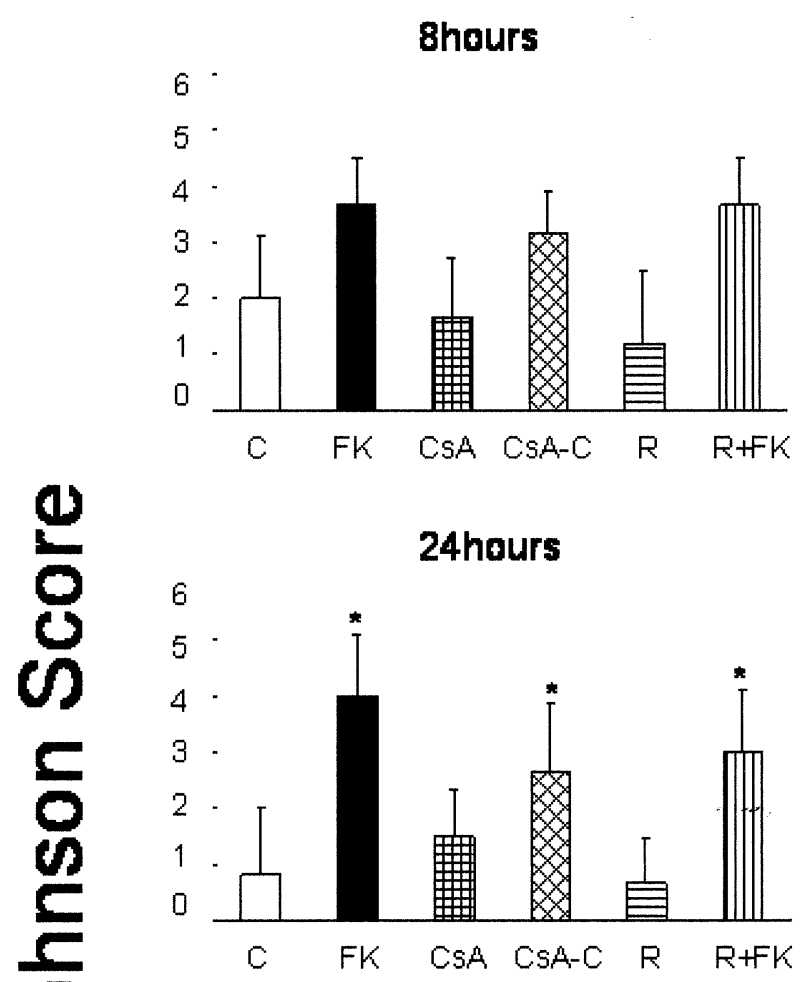

Figure 1. Neurologic outcome graded by Johnson's score. Group C, Control group; group FK, FK506 pretreatment group; group CsA, cyclosporine A pretreatment group; group CsA-C, cyclosporine A chronic administration group; group $R$, rapamycin pretreatment group; group $R+F K$, rapamycin administration before FK506 pretreatment group. *Statistically significant difference compared with group C (24 hours, FK $\boldsymbol{P}=.007$, CsA-C $\boldsymbol{P}=.024, \mathrm{R}+\mathrm{FK} \boldsymbol{P}=$ .008; 48 hours, FK $P=.007$, CsA-C $P=.024, R+F K P=.008$ ).

first time that rapamycin, which binds to FKBP12 without calcineurin inhibition, does not have a protective effect in the same model. The protective effect of cyclosporine A could be shown by chronic administration of $20 \mathrm{mg} / \mathrm{kg}$, but we failed to show it by single preischemic administration of $30 \mathrm{mg} / \mathrm{kg}$ - the dose that was reported effective in the previous study by postischemic administration. ${ }^{4}$

The result that FK506, but not rapamycin, showed a protective effect is consistent with previous reports. ${ }^{3,8}$ 

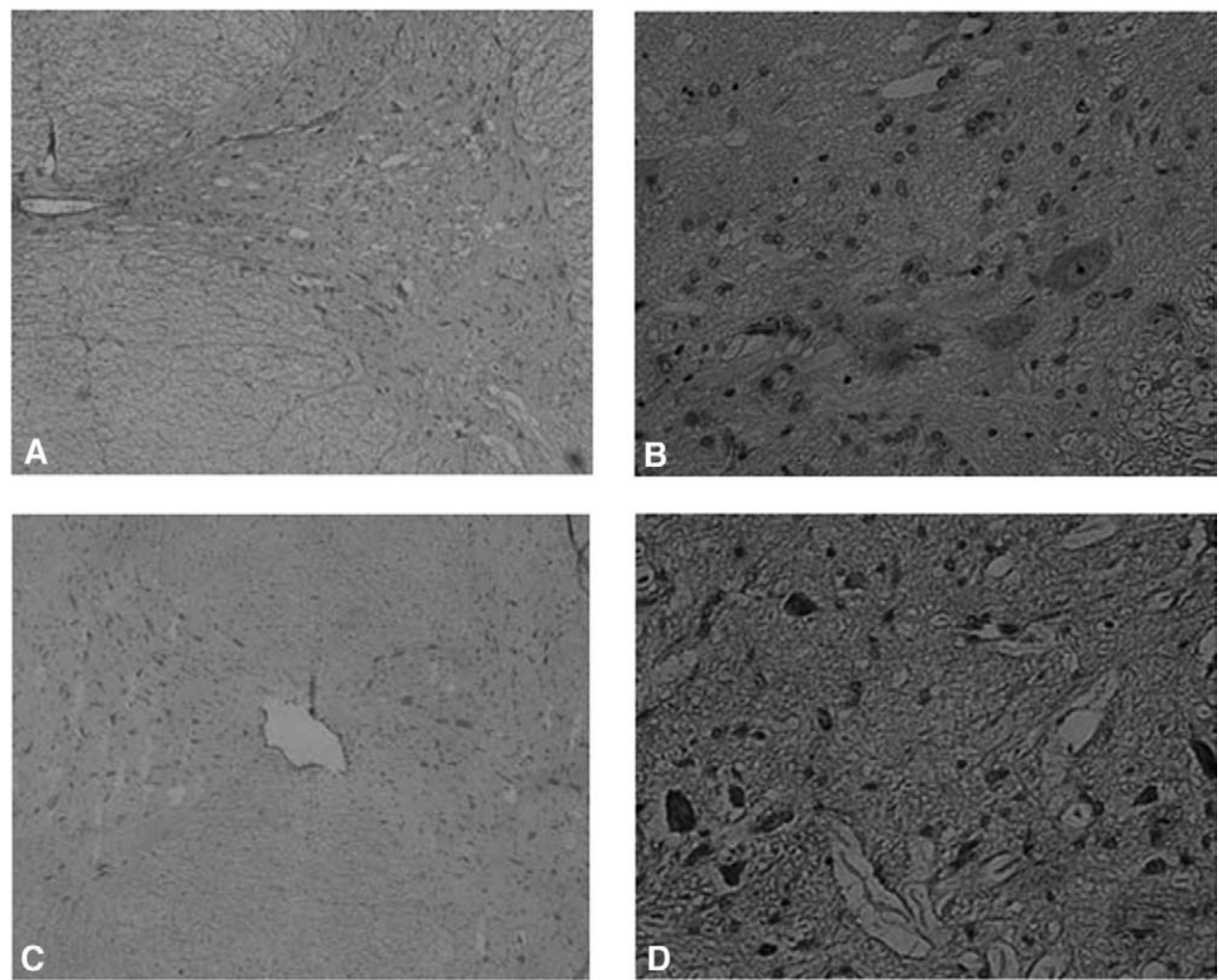

Figure 2. Light microscopy of spinal cord tissue stained with hematoxylin and eosin. a, FK506 pretreatment group (original magnification, $100 \times$ ); b, FK506 pretreatment group (original magnification, $400 \times$ ); c, control group (original magnification, $100 \times$ ); d, control group (original magnification, $400 \times$ ). In the FK506 pretreatment group, many large motor neurons were seen in the anterior horn, in which nuclear structures were retained. In the control group, the gray matter had vacuums in places, and remaining large motor neurons showed shrinkage and chromatic agglutination.

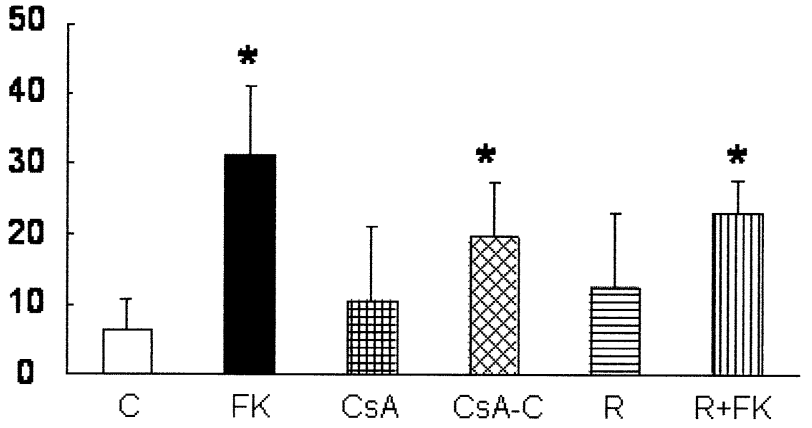

Figure 3. Number of anterior horn cells in each group. Group $C$, Control group; group FK, FK506 pretreatment group; group CsA, cyclosporine A pretreatment group; group $C s A-C$, cyclosporine $A$ chronic administration group; group $R$, rapamycin pretreatment group; group $R+F K$, rapamycin administration before FK506 pretreatment group. *Statistically significant difference compared with group C (FK $\boldsymbol{P}=.0002$; CsA-C $\boldsymbol{P}=.0044$; R+FK $P<$.0001).

FK506 $1 \mathrm{mg} / \mathrm{kg}$ has been reported effective in several animal models of transient cerebral ischemia. ${ }^{9-11}$ LangLazdunski and colleagues ${ }^{5}$ have also reported a protective effect of FK506 $1 \mathrm{mg} / \mathrm{kg}$ in the rat model of transient spinal cord ischemia. The dose of rapamycin was also set at 1 $\mathrm{mg} / \mathrm{kg}$ because it has almost the same structure and molecular weight as FK506. Sharkey and Butcher ${ }^{3}$ have reported in a rat model of brain ischemia that rapamycin $1 \mathrm{mg} / \mathrm{kg}$ did not protect the brain. Although rapamycin binds with high affinity to FKBP12 at the same site as FK506, rapamycinbound FKBP12 interacts not with calcineurin, but also with a different target called (Rapamycin and FKBP-12 Target) (RAFT), ${ }^{1}$ and this may explain the different behavior of the 2 drugs.

The reason that single preischemic administration of cyclosporine A $30 \mathrm{mg} / \mathrm{kg}$ was not effective may be explained by the poor blood-brain barrier permeability of the drug, ${ }^{12}$ because a protective effect could be shown by chronic administration of $20 \mathrm{mg} / \mathrm{kg}$. A similar dosage schedule has been reported effective to overcome the problem of blood-brain barrier permeability in an in vivo model of brain ischemia. ${ }^{2}$ Although a protective effect of postischemic single administration of cyclosporine A $30 \mathrm{mg} / \mathrm{kg}$ was shown in the previous study in a rabbit model of spinal cord ischemia, ${ }^{4}$ the discrepancy may be explained by the differ- 
ence in the timing of administration. Because the bloodbrain barrier may be damaged after ischemia, cyclosporine A can more readily be distributed to the cord by postischemic administration.

Despite many studies, the mechanisms of the neuroprotective action of cyclosporine A and FK506 remain controversial. Many studies have suggested that neuronal calcineurin inhibition-for example, by preventing neuronal nitric oxide synthase activation ${ }^{13}$ or by preventing activation of the proapoptotic protein $\mathrm{BAD}^{14}$-mediates neuroprotective action. In addition, anti-inflammatory actions of these drugs, such as suppression of the proinflammatory cytokines through their effects on leukocyte calcineurin, may also be involved. The results of this study - that FK506 and chronic administration of cyclosporine A, but not rapamycin, had neuroprotective effects-agree with the involvement of these mechanisms.

Several mechanisms other than calcineurin inhibition have been reported which may also explain the neuroprotective action of FK506 and cyclosporine. Cyclosporine A has been reported to exert its neuroprotective effect not only as a calcineurin inhibitor, but also as a blocker of mitochondrial permeability transition pores. ${ }^{15}$ The latter action is mediated through the mitochondrial matrix-specific cyclophilin D and is not observed for FK506. ${ }^{15}$ FK506 has been reported to have an antiapoptotic action that is not mediated through calcineurin inhibition, ${ }^{10,11,16}$ and involvement of neuronzal calcineurin inhibition in the mechanism of neuroprotective action was not supported in several studies. ${ }^{16,17}$ The result that FK506 tended to be more effective than chronic administration of cyclosporine A may suggest involvement of such pathways. However, it may also be explained by the differences in drug distribution to the spinal cord.

FK506 also has a neuroregenerative effect, as evidenced by the promotion of neurite outgrowth, in addition to its neuroprotective effects. ${ }^{18}$ Recent studies have suggested that FKBP52, a component of the steroid receptor complex, but not FKBP12, is necessary for this effect. ${ }^{19}$ Promotion of neurite outgrowth, however, is observed 2 to 6 days after FK506 treatment, and the neuroprotective effect is shown just after reperfusion. In addition, rapamycin, which does not have the neuroprotective effect, has also been reported to have a neuroregenerative effect. ${ }^{18}$ Therefore, the neuroregenerative effect does not seem to explain the neuroprotective effect seen in this study.

Our result that rapamycin $1 \mathrm{mg} / \mathrm{kg}$ administered before FK506 did not completely inhibit the neuroprotective effect of FK506 $1 \mathrm{mg} / \mathrm{kg}$ is confusing. Because rapamycin competes the binding site to FKBP12 with FK506, it should have inhibited the effect of FK506 if calcineurin inhibition were the mechanism of its action. This confusing result may be explained by an insufficient dose of rapamycin relative to that of FK506.
Sharkey and Butcher ${ }^{3}$ have reported in a rat model of brain ischemia that rapamycin $1 \mathrm{mg} / \mathrm{kg}$ blocked the protective effect of FK506 $0.1 \mathrm{mg} / \mathrm{kg}$. Therefore, further studies with different doses of the drugs will be required in this aspect, and the role of calcineurin inhibition in their mechanism remains speculative. Other effects through different pathways cannot be excluded before further study.

Clinically, FK506 is much more attractive than cyclosporine $\mathrm{A}$ in that a single administration of $1 \mathrm{mg} / \mathrm{kg}$ has a strong neuroprotective effect. Actually, the administration of cyclosporine A $20 \mathrm{mg} / \mathrm{kg}$ for 9 days was lethal in 2 of 8 animals in this study and is not practical. Recently it has been reported that a lower dose of FK506 is also effective for protecting the brain from ischemia. ${ }^{8,17}$ Therefore, further studies with smaller doses will be required to determine the optimal dosage schedule of FK506.

\section{References}

1. Sabatini DM, Lai MM, Snyder SH. Neural roles of immunophilins and their ligands. Mol Neurobiol. 1997;15:223-39.

2. Shiga Y, Onodera H, Matsuo Y, Kogure K. Cyclosporin A protects against ischemia-reperfusion injury in the brain. Brain Res. 1992;595: 145-8.

3. Sharkey J, Butcher SP. Immunophilins mediate the neuroprotective effects of FK506 in focal cerebral ischaemia. Nature. 1994;371:336-9.

4. Sato M, Horinouchi T, Sakurai M, Murakami N, Sato S, Kato M. Cyclosporin A reduces delayed motor neuron death after spinal cord ischemia in rabbits. Ann Thorac Surg. 2003;75:1294-9.

5. Lang-Lazdunski L, Heurteaux C, Dupont H, Rouelle D, Widmann C, Mantz J. The effects of FK506 on neurologic and histopathologic outcome after transient spinal cord ischemia induced by aortic crossclamping in rats. Anesth Analg. 2001;92:1237-44.

6. Wakamatsu Y, Shiiya N, Kunihara T, Watanabe S, Yasuda K. The adenosine triphosphate-sensitive potassium channel opener nicorandil protects the ischemic rabbit spinal cord. J Thorac Cardiovasc Surg. 2001;122:728-33.

7. Johnson SH, Kraimer JM, Graeber GM. Effects of flunarizine on neurological recovery and spinal cord blood flow in experimental spinal cord ischemia in rabbits. Stroke. 1993;24:1547-53.

8. Bochelen D, Rudin M, Sauter A. Calcineurin inhibitors FK506 and SDZ ASM 981 alleviate the outcome of focal cerebral ischemic/ reperfusion injury. J Pharmacol Exp Ther. 1999;288:653-9.

9. Yagita Y, Kitagawa K, Matsushita K, Taguchi A, Mabuchi T, Ohtsuki T, et al. Effect of immunosuppressant FK506 on ischemia-induced degeneration of hippocampal neurons in gerbils. Life Sci. 1996;59:1643-50.

10. Herr I, Martin-Villalba A, Kurz E, Roncaioli P, Schenkel J, Cifone MG, et al. FK506 prevents stroke-induced generation of ceramide and apoptosis signaling. Brain Res. 1999;826:210-9.

11. Brecht S, Schwarze K, Waetzig V, Christner C, Heiland S, Fischer G, et al. Changes in peptidyl-prolyl cis/trans isomerase activity and FK506 binding protein expression following neuroprotection by FK506 in the ischemic rat brain. Neuroscience. 2003;120:1037-48.

12. Uchino H, Elmer E, Uchino K, Li PA, He QP, Smith ML, et al. Amelioration by cyclosporin A of brain damage in transient forebrain ischemia in the rat. Brain Res. 1998;812:216-26.

13. Dawson TM, Steiner JP, Dawson VL, Dinerman JL, Uhl GR, Snyder SH. Immunosuppressant FK506 enhances phosphorylation of nitric oxide synthase and protects against glutamate neurotoxicity. Proc Natl Acad Sci U S A. 1993;90:9808-12.

14. Springer JE, Azbill RD, Nottingham SA, Kennedy SE. Calcineurinmediated BAD dephosphorylation activates the caspase-3 apoptotic cascade in traumatic spinal cord injury. J Neurosci. 2000;20:7246-51.

15. Uchino H, Minamikawa-Tachino R, Kristian T, Perkins G, Narazaki M, Siesjo BK, et al. Differential neuroprotection by cyclosporin A and 
FK506 following ischemia corresponds with differing abilities to inhibit calcineurin and the mitochondrial permeability transition. Neurobiol Dis. 2002;10:219-33.

16. Klettner A, Baumgrass R, Zhang Y, Fischer G, Burger E, Herdegen T, et al. The neuroprotective actions of FK506 binding protein ligands: neuronal survival is triggered by de novo RNA synthesis, but is independent of inhibition of JNK and calcineurin. Brain Res Mol Brain Res. 2001;97:21-31.

17. Toung TJ, Bhardwaj A, Dawson VL, Dawson TM, Traystman RJ, Hurn PD. Neuroprotective FK506 does not alter in vivo nitric oxide production during ischemia and early reperfusion in rats. Stroke. 1999;30:1279-85.

18. Lyons WE, George EB, Dawson TM, Steiner JP, Snyder SH. Immunosuppressant FK506 promotes neurite outgrowth in cultures of PC12 cells and sensory ganglia. Proc Natl Acad Sci U SA. 1994;91:3191-5.

19. Gold BG, Densmore V, Shou W, Matzuk MM, Gordon HS. Immunophilin FK506-binding protein 52 (not FK506-binding protein 12) mediates the neurotrophic action of FK506. J Pharmacol Exp Ther. 1999;289:1202-10.

\section{Availability of Journal back issues}

As a service to our subscribers, copies of back issues of The Journal of Thoracic and Cardiovascular Surgery for the preceding 5 years are maintained and are available for purchase from Elsevier Inc. until inventory is depleted. Please write to Elsevier Inc., Subscription Customer Service, 6277 Sea Harbor Dr, Orlando, FL 32877, or call $800-654-2452$ or $407-345-4000$ for information on availability of particular issues and prices. 